\title{
Gidatutako Unibertsitate Debatea: erizain-gaitasunak trebatzeko hezkuntza-metodologia aktiboa
}

\author{
(Guided University Debate: an education active methodology to train \\ nursing skills)
}

\author{
Amaia Cuesta*, Marta Arrue
}

Medikuntza eta Erizaintza Fakultatea, Donostia (UPV/EHU)

\begin{abstract}
LABURPENA: Erizaintza-zainketek pentsamendu kritikorako gaitasuna eta argudiatzeko ahalmena eskatzen dute, eta, hortaz, unibertsitate-hezkuntzan haiek garatzeko erronka planteatzen da. Psikologiaren eta hezkuntzaren harreman estua hezkuntza-metodologia aktiboen oinarrietan islatzen da. Izan ere, Piaget eta Vigotsky psikologo garaikideen lerroari jarraituz, konstruktibismoa da metodo horien funtsa. Hortaz, ikaslea protagonistatzat hartuta, aurretiko jakintzan oinarrituko da modu aktiboan ezagutza sortzeko. Hezitzaileak, ikaslearen barne-prozesua gidatuko du, eta jakin-mina piztu. Gidatutako Unibertsitate Debatea erizaintzaren diziplinan garrantzizko diren gaitasun horiek trebatzeko irakaskuntza-tresna aktibotzat proposatzen da artikulu honetan. Euskal Herriko Unibertsitatean (UPV/EHU) erizaintzako graduan metodologia honen ezarpenarekin ikasleen asebetetzea lortzeaz gain, etorkizuneko praktika klinikoa aberatsagoa egingo duten konpetentziak lantzeko aukera ematen duela ikusi da. Ikasketa-prozesu aktiboek eta Gidatutako Unibertsitate Debateak, bereziki metodologia tradizionalarekin alderatuz, emaitza onuragarriak erakutsi dituzte; informazioa sintetizatu, analizatu eta ebaluatzeko ahalmena hobetzeaz gain, argudiatzeko gaitasuna ere trebatzen baita. Gidatutako Unibertsitate Debatearen bidez, hezkuntza-kulturan presente dauden praktikak aldatu eta, eduki teorikoetatik haratago, apustu egiten da erizainen eginkizun profesionalean erabilgarriak izango diren gaitasun horiek garatzearen alde.
\end{abstract}

HITZ GAKOAK: Konstruktibismoa, Metodologia aktiboak, Debatea, Erizaintza, Hezkuntza.

\begin{abstract}
Nursing care requires critical thinking and the ability to argue. Therefore, developing these skills becomes a challenge in Higher Education. The close relationship between psychology and education is reflected in the active methodologies and following the ideas of contemporary psychologists Piaget and Vigotsky, the basis of these methods is constructivism. Hence, as the protagonist of his/her own learning, the student will rely on the previous knowledge to build new one. The educator will guide the student's internal process provoking curiosity. In this article, Guided University Debate is proposed as a teaching active tool to develop important skills in the nursing discipline. The implementation of this methodology in the nursing degree at the University of the Basque Country (UPV/EHU), has achieved high student satisfaction as well as giving the opportunity to put skills into practice that will enrich the clinical practice of the future. Active learning and specifically the Guided University Debate, have shown more positive results compared to the traditional methodology. In addition to improving student's ability for synthesis, analysis and evaluation of information, it also progresses the ability to reason. The implementation of Guided University Debate can change the practices present in the educational culture. Beyond the theoretical content, this new approach promotes the development of relevant skills for the practice of the professional role of nursing.
\end{abstract}

KEYWORDS: Constructivism, Active learning, Debate, Nursing, Education.

* Harremanetan jartzeko / Corresponding author: Amaia Cuesta. Medikuntza eta Erizaintza Fakultatea, Donostiako Erizaintza Atala. UPV/EHU. J. Beguiristain Dk. pasalekua, 105 (20014 Donostia-San Sebastián, Euskal Herria). amaiacuestazigorraga@gmail.com - https://orcid.org/0000-0002-1578-3533.

Nola aipatu / How to cite: Cuesta, Amaia; Arrue, Marta (2020). "Gidatutako Unibertsitate Debatea: erizain-gaitasunak trebatzeko hezkuntza-metodologia aktiboaw; Ekaia, 38, 2020, 129-140. (https://doi.org/10.1387/ekaia.21186).

Jasoa: 24 urria, 2019; Onartua: 11 abendua, 2019

ISSN 0214-9001 - eISSN 2444-3255 / (c) 2020 UPV/EHU

(c) (1) (9) Obra hau Creative 


\section{SARRERA}

Erizain bihurtzea prozedura ezberdinak egiteko gaitasuna garatzea baino gehiago da [1]. Rol profesionalean ezinbestekoak diren konpetentziak, hots, arrazoiketa klinikoan presente dauden horiek trebatzea osasunhezkuntzaren erronka bihurtzen da, horren ondorioz [2]. Arazoak ebazteko eta erabakiak hartzeko gaitasunean, eduki teorikoa ez da garrantzizkoa den bakarra. Sormenaz baliatu behar da erizaina egoera berri baten aurrean edo erabilitako interbentzioen eraginkortasun ezaren aurrean. Etengabeko egokitzapena ere bada erizaintzako egunerokotasunean presente dagoen eginkizuna pertsona, gaixotasuna eta testuingurua hirukote anizkoitzaren eta dinamikoaren errealitatean. Hortaz, egungo erizaintza-hezitzaileak eginbehar konplexua du, ikasketan pentsamendu kritikoa sustatzea barne hartzen baitu [3,4], pazientearen aurrean erabakirik egokienak hartzeko eta sor daitezkeen gatazkak bideratzeko. Osasunaren zaintzan erizainek duten desafioan hezi eta trebatzea ezinbestekoak diren gaitasunak garatzeko formula planteatzen dute hezkuntza-metodologia aktiboek.

Ukaezina da irakaskuntza-metodologia aktiboak erizaintzako ikasketetan aplikatuak izan direla formatu ezberdinetan (gela iraulia, arazoetan oinarritutako ikasketa, kasuen azterketa edo simulazio teknikak, besteak beste), metodologia tradizionalarekin alderatuz ikasleengan onura eragiten dutela erakutsiz $[4,5,6]$. Ikasleek prestatuago daudela detektatzen dute, eta baita praktika klinikoan konfiantza handiagoa dutela ere, erizaintzako oinarrizko gaitasunak garatzearen ondorioz eta egoera errealetara gerturatzeagatik [7, 8]. Aipatutakoak garrantzizko gaitasunak dira ikasle izatetik profesional izaterainoko trantsizio garaian. Bestalde, ikasleak metodologia honen abantaila ere onartzen du norbanakoaren ikasketa-prozesuaren eta gaitasun kritikoaren garapenean $[9,10]$, azken hau erizaintzaren praktikan oinarrizko gaitasuna. Gainera, irakasgaiarekiko motibazio eta interesa ere handitzen da [6].

Metodologia aktiboen garrantzia hainbeste ikertzaile eta ikasleren ahotan egonda, eta erizaintzako hezitzaileei aukerak zabaltzearen helburuarekin, aurkezten dugu Gidatutako Unibertsitate Debatea irakaskuntza estrategia aktiboa. GUDaren erroak esplikatzeaz gain, GUDa deskribatu eta estrategia honek duen potentziala ikasgelako esperientzia baten bitartez aurkeztuko da.

\section{GIDATUTAKO UNIBERTSITATE DEBATEAREN ERROAK}

Pertsonaren hezkuntza-prozesua aztertzeko jomugak psikologiaren eta hezkuntzaren mugak lausotzen ditu, historian zehar izan dituzten kezkak korapilatuta egon baitira. Piaget zein Vigotsky psikologo konstruktibis- 
tek jakintzaren sorreran pertsona erdigunean kokatu dute, eta hezkuntzametodologia aktiboek ildo beretik jarraitzen dute. Ikaslea errealitatearen hartzaile pasibo izatetik urrun, eta, hortaz, ezagutzaren iturri bakarra zentzumenezko esperientzia izatearen enpirismoaren ideia alde batera utziz, ikasketa-prozesu aktibo eta dinamikoaren alde egiten dute.

Aipatutako bi psikologo protagonistek badituzte sinplifikatu ezin diren ezberdintasunak [11]. Vigotskyk pertsona ingurune soziokultural batean murgilduta dagoen izakitzat ulertzen du: interakzioaren bitartez ezagutza eraikitzen duela defendatzen duen bitartean (testuinguruko ikuspegia), Piaget bakarkako ikasketaren aldekoa da. Vigotskyrentzat pentsatzea eginkizun sozial eta kolektiboa da, indibiduoen elkarreraginaren ondorioz sortua [12]. Piagetek, ordea, pertsona bakarkako ikastuntzat du, dakienean oinarrituta indibidualki aurretiko ezagupenak berreraikitzen ditu, norberaren barneko eraikuntza-prozesuari emanez garrantzia. Honela, kanpo-aldaketa batek pertsonarengan desoreka edo gatazka eragiten duenean, norbanakoak aktiboki orekara itzultzea bilatzen du [13].

Bi autoreek bat egiten dute ingurunearen garrantzia azpimarratzean, pertsonak esperientziak bizi dituen lekutzat deskribatuz, non jakin-mina eta ikasteko desira pizten dizkion [14]. Ikasgela ingurune bilakatu eta ikasleak sormenaren boterea garatzen duen espazioa izanik, irakasleari bitartekari papera egokitzen zaio, eta hala azaltzen dute.

Horren haritik, Vigotskyk Garapen Hurbileko Eremua esperientziadun batek ikasketa-prozesuan duen eragintzat deskribatzen du, honen interakzioaren bitartez jardueran lagunduz. Eremua izango litzateke ikasleak modu autonomoan arazoa ebazteko gaitasuna eta tutorearen laguntzaz lortutako mailaren arteko aldea. Hezkuntza-ekintzak duen eragina neurtzen du, hortaz. Irakasle-ikasle interakzioa handitzen den neurrian, ikaslearen ikasketak ere gora egiten du; ikaslea dakienaz ohartzen baita, eta kontzeptu berriak aurrekoekin lot baititzake [15]. Gaitasunak eskuratzeko prozesuaren gidan ikaslearengan interesa piztea hezitzailearen funtsa da joera konstruktibistan oinarritzen den hezkuntzan, ikasketa-prozesu esanguratsua sorraraziz. Determinatzaile indibidualak kontuan hartu behar dira, hortaz, norberaren adimenaz gaindi baita motibazioa zein ikas-estiloa [16], eta motibatzailea, aholkulari fidagarria eta eredugarria den mentorea izango da ikasleengan gogoa, kemena eta inspirazioa sustatuko duena [17].

Piagetek hezitzailea orientatzaile edo gidaritzat ere definitzen du ikasketa-prozesuan, betiere ikaslea informazioa garatzen duen subjektu aktibotzat edukiz. Beraz, hezitzaileak garapenean mesede egiten duen ingurumena sortu eta egokitutako ekintzak erabiliko ditu ikasleak bere kabuz deskubritu eta ikas dezan. «Umeari bere kabuz aurkitu zezakeen zerbait behar baino lehen erakusten zaionean, aurkikuntza galarazten zaio, eta, ondorioz, osotasunean ulertzea. Bistakoa da horrek ez duela irakasleak egoera 
esperimentalak diseinatu behar dituela ukatzen umearen sorkuntza errazteko» [18; egileen itzulpena].

Hortaz, Piageten edo Vigotskyren teoriak ikasgelan presente edukiz, irakasleak ikaslearen pentsamendua hobeto uler dezake eta adimenaren egituraketa ezagutuz bere esku-hartzeak bideratu ditzake. Piagetek, ikasleari gatazka bat planteatzen zaionean, honen ezagutzaren berreraikuntza gidatuz konponduko luke konfliktoa, prozesu horren emaitza ezagutzaren sorrera izanik. Vigotskyk irakaskuntza elkarlanean eta kolaborazioan oinarrituko luke, eta ezagutza litzateke ikasleak ingurune sozialetik abiatutako eraikuntza.

Ikasketa esanguratsuan ezin da Ausubelen ekarpena aipatu gabe geratu: Piageten ideietan oinarrituz, ikasleak jaso eta barneratzen duenari egiten dio erreferentzia. Piageten antzera, ikasketa mekanikoa eta errealitateko informazioaren zuzeneko kopiaren ideia baztertuz, ikasleak dakiena aurreko jakintza eta kontzeptuekin erlazionatzean datza ikasketa adierazgarria. Hori dela eta, ikaslearen egitura kognitiboa ezagutzea garrantzitsua da, ikasketaekintzak antolatzeko eta aldaketa kontzeptuala bultzatzeko [19].

Laburbilduz, jakin-mina ardatz harturik, pertsona errealitatearen hartzaile pasibo izan beharrean errealitatean modu aktiboan ekinez, aurretik duen ezagutzan oinarrituz ikasten duela iragartzen dute konstruktibistek [12, 13, 19]. Hezkuntzaren eremura ekarriz, ikasketa-prozesuak balioa bere baitan duelarik, edukiak berak izan dezakeenera mugatzea saihestuz. Ezagunak dira filosofia zein psikologiako teorikoek hezkuntzaren eremuan egindako ekarpenak, beren oinarriak aplikatuz, eta bide horretan dihardute ikasketa aktiboaren alde apustu egiten duten metodologiek.

Baina erizainen hezkuntzan (irakaskuntza-ikaskuntza prozesuan), historikoki azalpen tradizionalean oinarritutako irakaskuntza egon da presente, non ikasleek jarrera pasiboan jasotzen baitute informazioa hitzaldi formatuan, ikasleen beharrak asetzeko eta garapen profesionalerako formatu eskasean [4]. Hori dela eta, erizaintzako ikasketetan, interesgarria da irakaskuntza tradizionala osatzen edo ordezkatzen duten metodologien alde egitea, eta egungo erizaintzako ikasleek ere esfortzuak gaitegia modu esanguratsuagoan ikastera bideratzea iradokitzen dute [20]. Ildo honetan aurkezen dugu hurrengo atalean Gidatutako Unibertsitate Debatea, hezkuntzametodologia aktiboa.

\section{GIDATUTAKO UNIBERTSITATE DEBATEA EZAGUTUZ}

Debatea heziketa-tresnatzat erabiltzen da txapelketa-formatuan [21]. eta baita unibertsitateko graduetan ere [10]. Osasunaren arloko unibertsitate-gradu ezberdinetan zehazki, ikasleen gaitasunen garapenean eraginkorra 
izan daitekeela erakusten hasi dira zenbait autore: pentsamendu kritikoa, talde-lana edo jende aurrean hitz egiteko trebetasuna lantzeko aukera ematen baitu $[22,23]$.

Argumentuak erakutsi eta defendatzen diren eztabaida da debatea, gai edo egoera polemikoak landu eta haietan inplikatzeko baliagarria izan daitekeen tresna bihurtuz. Era horretan, parte-hartze aktiboa sustatzen du, ez soilik jarreraren erakusketan, baita aurretiko prestakuntzan ere, gaiaren lanketan eta diskurtsoaren antolakuntzan, alegia. Piaget eta Vigotsky konstruktibisten oinarriak gogora ekarriz, ikaslea bere irakaskuntza-prozesuaren protagonista bilakatzen da, honi beharrezko erremintak emanez (irakaslea arduratuko da gidaritza-lanez), duen jakintzan oinarrituko da prozesuan sor daitezkeen gatazkei aurre egiteko, era horretan ezagutzak sortuz eta, hortaz, ikasiz. Zentzu horretan, badira ikertzaileak eta adituak adierazten dutenak ikasgelako debatea ikaslea ikasketa-prozesuan inplikatzea bultzatzen duen metodologia dela [21,24].

Debatearen bitartez ikasketa-prozesuan lantzen diren pentsamendu-gaitasunak Bloom Taxonomian goi-mailan kokatzen diren horiek dira: analisia, sintesia eta ebaluazioa [10, 23]; pentsamendu kritikoa trebatuz, hots, erizaintzako eginbeharren ardatz den hori. Bide horretatik, Gidatutako Unibertsitate Debatea erabili denean, argudiatzeko ahalmenaren hobekuntza sumatu da [22]. Ikasleak, maila gorenetan kokatzen diren gaitasunak trebatuz informazio gehiago atxikitzen duela frogatu da, ordea, hausnarketa eta garapen gehiagoren beharraren ondorioz [25].

GUDa prozesu bat den heinean, prozesu osoan zehar lantzen diren gaitasunak zehaztu dituzte Merida, Baratas eta Arruek [26]. Batetik, gaitasun instrumentalak bereizten dituzte, non ikasleak eskuratzen baitu informazioaren maneiua trebatzen duen berau analizatzeko, sintetizatzeko eta erabilgarria izateko helburuarekin antolatzen ikasiz. Bestetik, gaitasun interpertsonalek kooperazioari eta ulermenari egiten diote erreferentzia; bai eta ondokoaren errespetuari ere. Azkenik, sistemikoak diren gaitasunak zehazten dira, zeinak eremu ezberdinetako jakintzaren integrazioari egiten baitio erreferentzia, erizaintzaren zientzian, arlo teorikoaren eta praktikoaren arteko tartea elkartzea ahalbidetuz. Hau da, Bolonia prozesuak Goi Mailako Hezkuntzarako planteatzen den estrategiarekin bat egiten duela nabarmendu dute ikertzaileek.

GUDa hezkuntza-tresna aktiboa da, horrenbestez, ikaslea ikaste-prozesuaren erdigunean kokatzeaz gain, ikasgela jakin-mina pizteko eta sormena garatzeko espazio bihurtuko da, non irakasleak bitartekari papera beteko baitu. Bitartekari-lan horretan, Piageten garapen kognitiboaren teoria presente edukitzeak ikaslearen etengabeko asmaketa- eta berreraikuntza-prozesua ulertu eta hau indartzen lagunduko du, ikasketa esanguratsua izan dadin irakaskuntza-jarduerak egokituz. Vigotskyren pertsonen arteko ha- 
rremanen funtsezko ideiak, hezkuntza eta interakzio sozialaren lotura estua gogora dakarkigu, ikaskidetza, hau da, taldean eta kooperazioan aritzea sustatzea hezitzailearen eginbeharren artean kokatuz, horretarako ingurune aproposena eraikiz. Kontzepzio konstruktibista ikasgelara ekarriz, giro estimulagarria sortuko da ikaslearen jardueraren aldamioen bitartez [12, 15] (irakaslearen laguntza) eta elkarrekintzako jarduerak bultzatuz edukiak barneratzeko zein ikaslearen abileziak hobetzeko eremu instrumental, interpertsonal eta baita gaitasun sistemikoetan ere.

Hori guztia bizitzeko aukera izan zuten, 2018-19 ikasturtean, Euskal Herriko Unibertsitateko «Osasuna, gaixotasuna, kultura eta zainketak» irakasgaian matrikulatutako ikasleek $(\mathrm{n}=18)$.

\section{GIDATUTAKO UNIBERTSITATE DEBATEAREN ESPERIENTZIA BERRI BAT}

Jarraian, Euskal Herriko Unibertsitateko Erizaintzako Graduan Gidatutako Unibertsitate Debatearen inplementazioaren esperientzia azalduko da.

Garbi izan beharreko aurreneko ideia da GUDa fase ezberdinetan banatzen den prozesua dela, zeinak, ikasgelako debateaz beraz gain, hara iritsi arteko lanketa jasotzen baitu. Astez aste egin beharrekoak eta arauak Arrueren lan-taldeak [22] deskribatutakoaren arabera jarraitu ziren (ikus 1. taula).

Debate-txapelketetan gertatzen den bezala, hasieran galdera dikotomiko bat planteatu zitzaien ikasleei; eguneratua eta erizaintza-zientziarekin erlazionatua: Txertaketa modu sistematiko eta nahitaezkoan egokia da? Talde bakoitzak aldeko eta aurkako posturak defendatzeko adinako argumentuak garatu eta eraiki zituen 4 astean zehar (debate-eguna iritsi arte ez da jakiten zer jarreraren defentsa egin behar den, minutu batzuk lehenago zoriz hautatzen baita). Modu ez-presentzialean eta talde-lanean eraman zen aurrera ebidentzian oinarritutako argumentuen bilaketa. Prozesu guztian zehar, irakaslearen figura presente egon zen lana gainbegiratu eta gidatzeko. Talde-lan ez-presentzial hori bideratu ahal izateko sortu zen, hain zuzen, «Debatearen txokoa» irakasgaiaren plataforma birtualean; ikasle eta irakasle-orientatzailearen arteko interakzioa erraztea eta ikaslearen garapen potentziala (Vigotskyren Hurbileko Garapen Eremuaz oroituz) indartzea ahalbidetzen zuen tresna. Han, astero galdera detonatzaile bat (2. taula) argitaratzen zen bilaketa bibliografikoan laguntzeko asmoz, eta horrez gain, irakasleari ikasleek eraikitako argumentuak bidaltzeko aukera zegoen honek feedback-a eman zezan. Astero planteatutako galderari erantzuteko aurkako eta aldeko ebidentzia bilatzearen ondorioz, eztabaidan erabili ahal izateko argumentuak eraikitzen zituzten ikasleen eta irakaslearen arteko interakzioaren bitartez. 
1. taula. Gidatutako Unibertsitate Debatearen ezaugarriak

\begin{tabular}{|c|c|c|c|}
\hline Astea & $\begin{array}{l}\text { GUDaren } \\
\text { fasea }\end{array}$ & Modalitatea & Jarduerak \\
\hline 1 & $\begin{array}{l}\text { 1. fasea } \\
\text { Sarrera }\end{array}$ & $\begin{array}{l}\text { Presentziala } \\
\quad(2 \text { ordu) }\end{array}$ & $\begin{array}{l}\text { - Ekintza aurkeztu eta taldeak ausaz sortu. } \\
\text { - Galdera planteatu: } \\
\text { - Galderaren analisia. } \\
\text { - Dagoen jakintza aztertu. } \\
\text { - Helburuak zehaztu. }\end{array}$ \\
\hline $2-4$ & $\begin{array}{c}\text { 2.fasea } \\
\text { Debatearen } \\
\text { prestaketa }\end{array}$ & $\begin{array}{l}\text { Ez-presentziala } \\
\quad(8 \text { ordu) }\end{array}$ & $\begin{array}{l}\text { - Taldeka ebidentziak bilatu (alde eta aurka). } \\
\text { - Taldeka argumentuak eraiki (aldekoak eta aur- } \\
\text { kakoak). } \\
\text { - Taldekide bakoitzak debatean izango duen rola } \\
\text { landu. }\end{array}$ \\
\hline 5 & $\begin{array}{c}\text { 3.fasea } \\
\text { Debatea } \\
\text { ikasgelan }\end{array}$ & $\begin{array}{l}\text { Presentziala } \\
\quad(2 \text { ordu })\end{array}$ & $\begin{array}{l}\text { - Defendatu beharreko jarrera zozketatu. } \\
\text { - Prestaketa (10 min). } \\
\text { - Debatea ( } 20 \mathrm{~min}) \text { : } \\
\text { - Sartzailea }(2 \mathrm{~min}) \text {. } \\
\text { - } 1 . \text { argudiatzailea }(3 \mathrm{~min}) \\
\text { - 2. argudiatzailea }(3 \mathrm{~min}) \\
\text { - Ondorioztatzailea }(2 \mathrm{~min})\end{array}$ \\
\hline 6 & $\begin{array}{c}\text { 4.fasea } \\
\text { Feedback-a }\end{array}$ & $\begin{array}{l}\text { Presentziala } \\
\quad(1 \text { ordu) }\end{array}$ & $\begin{array}{l}\text { - Eztabaidatutako jarrera teorikoen laburpena. } \\
\text { - Parte-hartzaileen komunikatzeko gaitasunen } \\
\text { feed-backa. } \\
\text { - Jardueraren ebaluazioa eta hobekuntza-propo- } \\
\text { samenak. }\end{array}$ \\
\hline
\end{tabular}

Iturria: Arrue et al. (2017).

2. taula. Galdera detonatzaileak

1. Txertoek immunitate-sistema indartzen dute?

2. Immunitate naturala txertaketa baino eraginkorragoa da?

3. Txertaketak beste gaixotasun batzuk sortzen ditu?

4. Txertaketan zein da arriskuaren eta eraginkortasunaren arteko balantza?

Debatea ikasgelan egiten den egunean, taldekide bakoitzak aurretik egokitzen zaion rol bat betetzen du (bakoitzaren ezaugarriak 3. taulan zehazten dira), eta hala jarraitu zen. Izan ere, talde bakoitza sartzaile batek, bi argudiatzailek eta ondorioez arduratzen zen laugarren kide batek osatzen 
zuten. Era horretan, ikasle guztien parte-hartzea bermatu eta pertsonaien arteko kooperazioa eta talde-lana sustatzeaz gain, bakarkako zein taldeko konpromisoa eskatzen du ikasketak prozesuan zehar.

3. taula. Gidatutako Unibertsitate Debatearen rolen ezaugarriak. Iturria: Arrue et al. (2017)

\begin{tabular}{c|l}
\hline \multicolumn{1}{c|}{ Rol-a } & \multicolumn{1}{c}{ Ezaugarriak } \\
\hline \multirow{3}{*}{ Sartzailea } & $\begin{array}{l}\text { - Kideak aurkeztu } \\
\text { - Taldeak defendatuko duen jarrera azaldu } \\
\text { - Taldeak defendatuko dituen argumentuak aurkeztu }\end{array}$ \\
\hline \multirow{3}{*}{ Argudiatzailea } & $\begin{array}{l}\text { - Argumentuak garatu: } \\
\text { Enuntziatu + Justifikatu + Ebidentziatu }\end{array}$ \\
& $\begin{array}{l}\text { - Aurkako taldearen argumentuak ezeztatu } \\
\text { Ondorioztatzailea }\end{array}$ \\
& $\begin{array}{l}\text { - Debatea laburtu } \\
\text { - Taldearen argumentuak defenditu } \\
\text { gehitzen) }\end{array}$ \\
\hline
\end{tabular}

Arau gehigarriei dagokienez, debatean ezarritako denboraren kontrola partaideek ikusteko moduan zuten kronometro baten bitartez egin zen. Bestalde, bi taldeak eztabaidatzen ari ziren bitartean, taldekideen arteko komunikazioa idatzizko mezuen bidez soilik baimendu zen. Argudiaketa-txandan zehar, aurkako taldeak galderak egiteko aukera zeukan, elkarrizketa ordenatu eta dinamikoa sortuz horrela. Debatean parte hartzen ari ez ziren gainerako ikasleek errubrika bat betetzen zuten ikaskideek egina ebaluatzeko.

6. astean, feedback-aren fasean, prozesua eta ikasitakoa ebaluatzeko aukera izan zen, bai eta proposatutako metodologiaren inguruan hausnartzeko aukera ere. Bertan, debatean erabilitako informazioa eta ebidentziak landu ziren, batetik, eduki teorikoa jorratzeko asmoz. Bestetik, ikasle bakoitzaren komunikazio-teknikak aztertu ziren, hobekuntzarako proposamenak aurkeztuz.

\section{EMAITZAK ETA EZTABAIDA}

Metodologia aktiboen inplementazioa jarduera pedagogiko ezberdin batekin saiatzea baino gehiago da. Oinarri filosofikoak dituen tresna iza- 
nik, hezitzailearen zein ikasleen ikuskeraren aldaketa eskatzen du [25], eta baita hezkuntza kulturaren interpretazioan aldaketa ere [27]. Metodologia aktiboen erabilerak ikaslean inpaktu onuragarria eragiteaz gain, irakasleriari bereziki erronka berriak planteatzen eta zailtasunak gehitzen dizkio, eta hausnarketarako bidea ireki.

GUDaren inplementazioaren esperientziak rol profesionalean oinarrizko diren gaitasunak trebatzeko aukera ematen du: gaitasun kritikoa, besteak beste. Hala frogatu dute debatearen inguruan argitaratutako hainbat ikerketak [10, 23, 24] eta baita GUDaz baliatuz egindako lehen emaitzek ere [26]. Esperientzia honetan ere, ikaslearengan duen eragin positiboa erakutsi da entzuteko eta hitz egiteko gaitasunean, esaterako, eragina agerian utziz debateak errepikatu ahala, ondorengo taldeetan hobekuntza sumatzen zen eta. Aipatutakoan erreparatu da beste saiakera batzuetan [21], erabilitako formatuan bariazioak badaude ere, errepikapenaren poderioz, aurretik prestatutako testuarekiko dependentzia gutxituz joaten dela ikusi baita. Ezin da ahaztu GUDarekin teoriaren eta praktikaren dikotomiaren transferentzian ere lagundu dezakeela horren ezaguna den ikasle izatetik gaitutako erizain izaterako trantsizio-estresean [28] ere eraginez.

GUDaren esperientziaren inguruan zuten iritzia baloratzeko, inkesta bat pasa zitzaien parte-hartzaile guztiei, non \%100ek proposatutako metodologiaren alde apustu egingo luketela adierazi baitzuten hurrengo irakasgairen batean aukera izango balute. Izan ere, \%66,7ak metodologia tradizionalagoekin alderatuz ikasten «gehiago» lagundu zuela adierazi zuen, eta gainerakoek «asko» lagundu zietela azpimarratu zuten. GUDak metodologia tradizionalarekin konparatuz ikasten «gutxiago» edo «berdin» lagundu zuela erako erantzunik ez zen jaso. Hari beretik, erizain-gaitasun klinikoetan lorpen nabariagoak ikusi dira, orobat, konparaziozko ikerkete$\tan [29]$.

Adierazi bezala, irakasleak prozesua gidatzeko eginkizuna du oinarritzat konstruktibistadun irakaskuntza-erremintetan. Deskribatutako esperientzian plataforma birtualaren bitartez ebaluazio jarraitua egin zuen. Honen bidez, ikaslearen prozesua behatu, motibazioa suspertu eta ikasleak landu nahi diren gaitasunetara bideratzeko orientazioak ematen zituen irakasleak. Prozesu honetan, eskuratutako informazioa kudeatzeko eta sintetizatzeko hobekuntza nabaria izan zen oso. Irakasleak, ikasleek jasotako ebidentziaren laburpenak egiteko tendentzia orokorretik, argumentuak ondo eraikitzen ikasi zutela antzeman baitzuen, ideiak arrazoituz eta haiek ebidentziatuz. Hona hemen talde batek «Debateren txokoan» utzitako argudiaketaren eta sintesi gaitasunaren eboluzioaren adibide bat:

Txertoak oso seguruak dira eta sor ditzaketen erreakzio gehienak arinak eta epe oso motzekoak izaten dira. Izan ere, txertorik gabe, asaldura eta heriotza gehiago egongo lirateke eta txertaketa programak desager- 
tuko balira, txertoekin kontra egiten diegun gaixotasunak agertuko lirateke berriro (industrializatuta dauden herrialdeetan ere). (3. taldea, 1. astean)

OMEk txertaketa segurua dela baieztatzen du, erreakzioak arinak edo epe motzekoak izanik (onurak kalteak gaindituz) eta erabilgarriak dira hainbat asaldura eta heriotza saihesteko. (3. taldea, 4. astean)

Hori dela eta, GUDa argudiatzeko gaitasuna lantzeko eta hau hobetzeko baliagarria dela esan daiteke. Ikasle gehienek $(\% 72,2)$ aipatu zuten jarraitutako metodologiak, irakasleak emandako orientazioak hain zuzen, haien beharrak «erabat» asetu zituztela, eta gainerakoek ere «asko» lagundu zituztela onartu zuten. Irakaslearen orientazioekin ez zen asetu gabeko ikaslerik geratu, inork ez baitzuen «gutxi» edo «nahiko» erantzun planteatutako galdera honetan.

Ebaluatutako atal orotan lortu diren emaitzak onak eta gogobetekoak izan dira. Izan ere, GUDean parte hartu duten ikasle guztiek planteatzen diren galderetan modu positiboagoan baloratzen duten aukera horien alde egin dute. Oro har, ikasleak landutako metodologia eta esperientziarekin «oso pozik» agertu ziren. Gainera, unibertsitatean «metodologia berritzaileak hedatzea» eta haiek «lehen kurtsoetatik aplikatzea» mesedegarria izango litzakeela aipatu zuten.

Herrialde eta ikasketa ezberdinetan metodologia aktiboekin izandako esperientziak modu positiboan baloratzen dituzte ikasleek. Hala ere, haien inguruan informazio gutxi dute eta izan dezaketen erabilgarritasuna ez dute ezagutzen [27].

\section{ONDORIOAK}

Erizaintzako ikasleek oinarrizko gaitasunak garatzeko eta haiek ikasi eta trebatzearen garrantziaz ohartzeko aukerak behar dituzte, hezkuntza espezializatuaren helburua baita ikasleak etorkizuneko erronketarako prestatzea.

Gidatutako Unibertsitate Debatearen esperientzia honek bat egiten du ikaste-prozesuan izan dezakeen eraginkortasuna erakusten aztertutako beste hainbat esperientziarekin. Hori dela eta, GUDa unibertsitatean irakaskuntza-erremintatzat proposatzen da, irakaskuntza tradizionalak saihesten dituen gaitasunak garatzen dituelako, ikasleak asebetetzera heldu eta etorkizuneko praktika klinikoan norberaren segurtasuna bermatzen duelako eta kalitatezko erizain-atentzio baten alde egiten duelako. Eduki teorikoa modu eraikitzailean, motibatzailean, desafiatzailean eta lankidetzan oinarrituta lantzeko aukera ematen dute metodologia aktiboek. 
Horretarako, garrantzitsua da tradizioz mantendu den hezkuntza-eredua aldatzea; teoria konstruktibistak oinarritzat hartuz, ikaslea erdigunera eramanez. Informazio eta formakuntza espezializatutik abiatuz, garrantzizkoa da norbanakoaren garapenean eragina duten hezitzaileen konpromisoa. Izan ere, hezkuntzak ikaslearengan ez ezik eginkizun profesionalean eragingo du, eta daraman joera gizartean ere islatuko da. Honela, gaitasun kritikoaren garapenera bideratutako erizaintza-hezkuntzaren alde apustu eginez, arrazonamendu kritikoa oinarritzat duen erizaintza garatuko da.

\section{BIBLIOGRAFIA}

[1] TESKERECI, G. eta BOZ, I. 2019. «I try to act like a nurse: a phenomenological qualitative study». Nurse Education in Practice, 37, 39-44.

[2] FORSBERG, E., ZIEGERT, K., HULT, H. eta FORS, U. 2014. «Clinical reasoning in nursing, a think-aloud study using virtual patients - a base for an innovative assessment». Nurse Education Today, 34 (4), 538-542.

[3] BONO-NERI, F. 2019. «Pedagogical Nursing Practice: Redefining nursing practice for the academic nurse educator». Nurse Education in Practice, 37, 105-108.

[4] WARD, M., KNOWLTON, M. C. eta LANEY C. W. 2018. «The flip side of traditional nursing education: A literature review». Nurse education in practice, 29, 163-171.

[5] LLOBET, J. R., ÁLVAREZ, M. R. eta VELEZ, O. C. 2015. «Aprendizaje basado en problemas, estudio de casos y metodología tradicional: una experiencia concreta en el grado en enfermería». Procedia-Social and Behavioral Sciences, 196, 163-170.

[6] ARRUE, M. eta CABALLERO, S. 2015. «Teaching skills to resolve conflicts with acute confusional syndrome patients in nursing using the Case Method (CM) ». Nurse Education Today, 35, 159-164.

[7] BURDEN, M. L., CARLTON, K. H., SIKTBERG, L. eta PAVLECHKO, G. 2015. «Flipping the classroom: Strategies for psychiatric-mental health course». Nurse educator, 40(5), 233-236.

[8] MCNAMARA, N. 2015. «Preparing students for clinical placements: The student's perspective». Nurse education in practice, 15(3), 196-202.

[9] ORTIZ, J. A. M., GONZÁLEZ, A. G., MARCOS, A. P., VICTORIA, M. eta NARDIZ, A. 2003. «Aprendizaje basado en problemas: una alternativa al método tradicional». Revista de Docencia Universitaria, 3(2), 79-85.

[10] HANNA, L. A. et al. 2014. «Using debate to teach pharmacy students about ethical issues». American journal of pharmaceutical education, 78(3), 57.

[11] LOURENÇO, O. PIAGET, J. eta VYGOTSKY, L. 2012. «Many resemblances and a crucial difference». New Ideas in Psychology, 30(3), 281-295.

[12] VYGOTSKY, L. 1978. Mind in society: The development of higher psychological processes. Harvard University Press, Cambridge MA. 
[13] PIAGET, J. 1969. Psicología y Pedagogía. Ariel, Barcelona.

[14] STOLTZ, T., PISKE, F. H. R., DE FÁTIMA QUINTAL DE FREITAS, M., D’AROZ, M. S. eta MACHADO, J. M. 2015. «Creativity in Gifted Education: Contributions from Vygotsky and Piaget». Online Submission, 6 , 64-70.

[15] VYGOTSKY, L. 1986. Thought and language. The MIT Press, Cambridge MA.

[16] GIL MOLINA, P. 2013. Hezkuntzaren Psikologia: teoria eta praktika. UPV/ EHU.

[17] KOEING, AM. 2019. «Mentoring: Are we living up to our profesional role as an educational leader? » Nurse Education Today, 79, 54-55.

[18] PIAGET, J. 1983. La psicología de la inteligencia. Crítica, Barcelona.

[19] AUSBEL, D. 1983. «Teoría del aprendizaje significativo». Fascículos de CEIF, 1, 1-10.

[20] MORREL-SCOTT, N. 2019. «Final year pre-registration student nurses' percepcions of which taught theoretical knowledge is important for practice». Nurse Education in Practice, 36, 151-156.

[21] MOOMALA, O., FAIZAH, M. eta AMIRI, F. 2013. «An English Debate League Competition among Lower Form Students: An Experiential Learning Activity». US-China Foreign Language, 11(11), 840-852

[22] ARRUE, M., UNANUE, S. eta MERIDA, D. 2017. «Guided university debate: Effect of a new teaching-learning strategy for undergraduate nursing students». Nurse Education Today, 59, 26-32.

[23] PEASAH, S. K. eta MARSHALL, L. L. 2017. «The use of debates as an active learning tool in a college of pharmacy healthcare delivery course». $\mathrm{Cu}$ rrents in Pharmacy Teaching and Learning, 9(3), 433-440.

[24] DOODY, O. eta CONDON, M. 2012. «Increasing student involvement and learning through using debate as an assessment». Nurse Education in Practice, 12, 232-237.

[25] KONOPKA, C. L., ADAIME, M. B. eta MOSELE, P. H. 2015. «Active teaching and learning methodologies: some considerations». Creative Education, 6(14), 1536-1545.

[26] MERIDA, D., BARATAS, I. eta ARRUE, M. 2016. «Guided University Debate (GUD): A new promising teaching and learning strategy for undergraduate nursing students». Nurse Education Today, 45, 69-71

[27] MOYA, E. C. 2017. «Using Active Methodologies: The Student's View». Procedia-Social and Behavioral Sciences, 237, 672-677.

[28] HIGGINS, G., SPENCER, R. L. eta KANE, R. 2010. «A systematic review of the experiences and perceptions of the newly qualified nurse in the United Kingdom». Nurse Education Today, 30(6), 499-508.

[29] SHIN, H., SOK, S., HYUN, K. S. eta KIM, M. J. 2015. «Competency and an active learning program in undergraduate nursing education». Journal of Advanced Nursing, 71(3), 591-598. 